\title{
Ciência, Religião, Psicologia: Conhecimento e Comportamento
}

\author{
Geraldo JośdePaiva ${ }^{12}$ \\ UniversidadedeSão Paulo, São Paulo
}

\begin{abstract}
Resumo
Comparam-se as respostas ao Questionário de Leuba relativo à crença dos cientistas num Deus pessoal ena imortalidade pessoal, obtidas em 1916, 1933, 1996 e 1998, as quais não apresentam grande variedade estatística. Apresentam-se, a seguir, algumas tentativas recentes de entendimento mútuo entre ciência e religião, com destaque das posições de Barbour, Haught e Hefner, que propõem a superação do confronto e da indiferença pelo diálogo e pela integração. Finalmente, discutese a relação do cientista com a religião do ponto de vista não mais epistemológico, mas psicológico, com base em pesquisa com pesquisadores universitários das áreas das ciências físicas, biológicas e humanas.

Palavraschave. Ciência e religião; psicologia da religião; conflito; diálogo.
\end{abstract}

Science, Religion, and Psychology: Knowledge and Behavior

\begin{abstract}
Answers given by scientists in 1916, 1933, 1996, and 1998 to Leuba's Questionnaire about their beliefs in God and personal immortality are compared. Some recent proposals of mutual acknowledgment between science and religion follow, with emphasis on Barbour's, Haught's, and Hefner's analyses, that suggest overcoming confrontation and indifference with dialogue and integration. Finally, scientists' personal relations to religion are discussed from a psychological, not epistemological, perspective based on an empirical study with Brazilian researchers in the areas of physical, biological and human sciences.

Keywords: Psychology of religion; science and religion; conflict; dialogue.
\end{abstract}

Ciência eReligião têm sido um binômio problemático em algumas áreas da cultura ocidental moderna. $\mathrm{O}$ acréscimo da Psicologia a esse binômio tem o sentido de destacar a extensão da ciência natural e biológica para a ciência humana e de apontar a dimensão psicológica que vincula o cientista à religião e o religioso à ciência.

Dealguma forma, ciênciae religião têm sido relacionadas como entidades em conflito. No entanto, as relações entre ambas não foram sempre conflituosas, nem na área acadêmica nem na área religiosa. Lembre-se a palavra sempre citada de Galileu relacionando o estudo natural dos corpos celestes e a doutrina bíblica: a Bíblia não nos diz como são feitos os céus, mas o que devemos fazer para chegar atélá. Recordese também queforam muitos os religiosos que propugnaram pela liberdade acadêmica (Marsden \& Longfield, 1992).

Em todo o caso, contemporaneamente, além do desencanto fin desèdecom a falta da "Resposta" às questões quea ciência sevem propondo (Horgan, 1997), presenciamos manifestações que vão de um certo desalento com a falta

\footnotetext{
${ }^{1}$ Versão de conferência proferida no XII Congresso Nacional do Corpo de Psicólogos e Psiquiatras Cristãos, Belo Horizonte, 7-10 de setembro de 2000.

${ }^{2}$ Endereço para correspondência: Departamento de Psicologia Social e do Trabalho do Instituto de Psicologia da USP. Av. Prof. Mello Moraes, 1721, 05595-000, São Paulo, SP. Fone (11) 3091-4184, Fax (11) 3091-4460. E-mail: gjdpaiva@usp.br
}

de novidade no trato das relações entre ciência e religião (Hutchinson, 1991), atéo entusiasmo com novos centros e sociedades dedicados ao tema: na Europa, a Sociedade Européia para o Estudo da Ciência eda Teologia (até1989, da Ciência eda Religião); nos Estados Unidos, o Centro para a Teologia easCiêndias Naturais, em Berkeley, CA, eo Centro para a Religião ea Ciênda, deChicago. A revistaZygon:Journal of Religion and Scienœ, cujo redator-chefeé Philip Hefner, recebe, para exame, no mínimo três vezes mais artigos do que é capaz de aceitar (Hefner, 1997). Não deixa de chamar a atenção, contudo, a direção geral desseinteresse: como observa Jones (1994) no caso da psicologia, não são os cientistas que debatem as relações da ciência com a religião, mas pessoas religiosas, inclusive cientistas, que se interessam pela questão. Um exemplo recente notável dessa direção é a Encíclica Fides et Ratio de João Paulo II. Mas podem citar-se outras publicações, como Spiritual Evolution: Sdentists disauss their beliefs (Templeton \& Giniger, 1998), com contribuições de cientistas representativos da Austrália, Inglaterra, Alemanha e dos Estados Unidos, nas áreas de astronomia, biologia, química, genética, medicina, físicae zoologia; Science\& Reigion: From conflid to conversation (Haught, 1995); as Tery Lectures, Belief in God in an Age of Scienœ(Polkinghorne, 1998) eo semprefamoso Religion in an Age of Science, atualizado pelo When ScienceM Mets Religion, deI. Barbour (Barbour, 1990, 2000), agraciado em 1999 com o Prêmio Templeton (Herrmann, 1999). 


\section{Leuba, Ontem e Hoje}

Desde cedo a Psicologia teve algum contato com a questão ciência/religião. Em 1914, o psicólogo suíço radicado nos Estados Unidos, James Leuba (1916), ligado a William James e reconhecido como um dos primeiros psicólogos da religião, realizou uma pesquisa empírica sobre "a fé (dos cientistas) num Deus que responde à prece e promete a imortalidade", isto é, o Deus do cristianismo. Seus sujeitosforam 1000 cientistas norte-americanos, físicos ebiólogos, aleatoriamente selecionados do American Men of Scienc. Dentre esses 1000, 400 eram designados como "grandes" cientistas. Essa pesquisa, denatureza "psicológica, antropológica eestatística", nas palavras do autor, não visava a investigar as relações epistemológicas entre ciência ereligião, mas sim a crença religiosa dos cientistas. Com isso, Leuba se antecipava à vertente de pesquisa que se interessa pela dinâmica psicológica do cientista em relação ao objeto religioso. Confirmação disso é a questão proposta por Leuba acerca do desjo de imortalidade. Os resultados encontrados por Leuba são apresentados na Tabela 1.
Em 1933, Leuba repetiu a aplicação do Q uestionário entre os "grandes" cientistas, com os resultados que aparecem na Tabela 2.

É digno de nota que Leuba, como bom psicólogo, reapresentou também o quesito relacionado com o desejo da imortalidade. Leuba previa que, com o tempo, a divulgação do conhecimento científico aumentaria a descrença religiosa principalmente por influência dos "grandes cientistas", detentores de "superior conhecimento, entendimento e experiência".

Oitenta anos depois, Larson eWitham (1997) repetiram o levantamento de Leuba entre os cientistas em geral, com os resultados apresentados na Tabela 3.

Larson eWitham comentam: "embora oitenta anosatrás a indicação de que quatro em 10 cientistas não acreditavam em Deus ou numa outra vida assustasse os contemporâneos, o fato de que hoje tantos cientistas (de fato, a mesma proporção) acreditam em Deuséigualmentesurpreendente" (1997, p. 435). Em outraspalavras, o conhecimento científico não alterou significativamente a crença ou a descrença em

Tabela 1

Respostas dos Cientistas em geral edos “Grande"” Cientistasao Questionário deLeuba (1916)*

\begin{tabular}{lcc}
\hline & Cientistas & "Grandes" cientistas \\
\hline Deus pessoal & & \\
\hline Crença & 42 & 28 \\
Descrença & 42 & 53 \\
Dúvida/agnosticismo & 17 & 21 \\
\hline Imortalidade pessoal & & \\
\hline Crença & 51 & 35 \\
Descrença & 20 & 25 \\
Dúvida/agnosticismo & 30 & 44
\end{tabular}

Nota. Valores percentuais arredondados. Fonte: Larson e Witham (1998).

Tabela 2

Respostas dos “Grandes" Cientistas ao Questionário deLeuba (1933)*

\begin{tabular}{lc}
\hline Deus pessoal & \\
\hline Crença & 15 \\
Descrença & 68 \\
Dúvida/agnosticismo & 17 \\
\hline Imortalidade pessoal & \\
\hline Crença & 18 \\
Descrença & 53 \\
Dúvida/ agnosticismo & 29
\end{tabular}

Nota. Valores percentuais arredondados. Fonte: Larson eWitham (1998). 
Deus e na imortalidade. Esse resultado sugere que muitos outros fatores influem na crença e na descrença dos profissionais da ciência.

Em 1998 os mesmos autores fizeram um novo levantamento, comparando agora os 400 "grandes" cientistas de Leuba com uma amostra mais "elitista" dos "grandes" cientistas contemporâneos da National Academy of Scienœes (Larson \& Witham, 1998, p.313) 3 . Quando se comparam os "grandes" cientistas aos cientistas em geral (Tabela 3), percebe-se que a proporção dos que não crêem em Deus e na imortalidade não só é maior como crescente. Os resultados estão apresentados na Tabela 4.
Resumindo as atuais relações entre ciência e religião nos Estados Unidos, Larson e Witham (1999) escrevem:

Ciência ereligião estão-se envolvendo num diálogo edebate maisativo, masum levantamento (amplo) indicaqueascrenças dos cientistas pouco mudaram desdea década de 1930 eque os cientistas mais eminentes estão mais ateus do que em qualquer outra época. (1999, p.78)

\section{Os Muitos Níveis de Causalidade}

Um ponto de inflexão nos estudos contemporâneos de nosso tema foi certamente provocado pelo físico e teólogo Ian Barbour. Depois de seu Issues in Science and

Tabela 3

ReppostasdosCientistasem geral ao Quetionánio deLeuba (1916) Reproposto por Larson eWitham (1996)*

\begin{tabular}{ll}
\hline Deus pessoal & \\
\hline Crença & 39 \\
Descrença & 45 \\
Dúvida/agnosticismo & 15 \\
\hline Imortalidade pessoal & \\
\hline Crença & 38 \\
Descrença & 47 \\
Dúvida/agnosticismo & 15 \\
\hline
\end{tabular}

N ota. Valores percentuais arredondados. Fonte: Larson e Witham (1997).

Tabela 4

Respostas dos "Grandes" Cientistas ao Questionário de Leuba (1916) Reproposto por Larson eWitham (1998)*

\begin{tabular}{lc}
\hline Deus pessoal & \\
\hline Crença & 7 \\
Descrença & 72 \\
Dúvida/ agnosticismo & 21 \\
\hline Imortalidade pessoal & \\
\hline Crença & 77 \\
Descrença & 23 \\
Dúvida/agnosticismo & \\
\hline
\end{tabular}

N ota. Valores percentuais arredondados. Fonte: Larson e Witham (1998).

\footnotetext{
${ }^{3}$ A amostra dos "grandes cientistas" de Larson e Witham (1998) é dita mais "elitista" do que a dos "grandes cientistas" de Leuba (1916) porque Leuba se guiou pelo rótulo "grandes cientistas" aposto aos nomes pelos editores do American Men of Scienœ, ao passo que Larson e Witham se valeram da relação
}

da National Academy of Sciences, que já assegurava o status de "grandes cientistas" nas edições antigas do American Men of Scienœ, que não mais apõe 0 rótulo "grande cientista" (Larson \& Witham, 1998). 
Religion (1966), Barbour publicou o influente Religion in an Age of Sdience (1990), que foram suas Gifford Lectures na Universidade escocesa de Aberdeen. Nessa obra, dedicada em particular à ciência física ebiológica, Barbour distingue quatro maneiras de se relacionar religião e ciência: 0 conflito, a independência, o diálogo e a integração. Como se vê, são maneiras que caminham no sentido do entendimento dessas duasformas culturais deconhecimento da natureza, do homem e de Deus.

Barbour ilustra o modo de conflito pelo materialismo científico eo literalismo bíblico: se se tomar como realidade fundamental do universo a matéria ou se se tomarem os enunciados bíblicos sem a compreensão do gênero literário no qual foram moldados, o conflito é inevitável, pois a contradição entre os dois pontos de partida é óbvia.

O modo deindependência reconhecequenão há medida comum entre ciência e religião no que respeita aos métodos e às linguagens. A posição de independência não é em si hostil nem à religião nem à ciência, mas é difícil de ser mantida a qualquer preço, pois um objeto comum psicologicamente exige, em algum momento, a convergência dos olhares. Uma expressão clássica desse modo é fornecida pela Academia Nacional de Ciências, dos Estados Unidos: "A religião e a ciência são reinos separados e mutuamente excludentes do pensamento humano, cuja apresentação no mesmo contexto leva a mal-entendidos tanto da teoria científica como da crença religiosa" (citado em Jones, 1994, p. 186).

O terceiro modo é o do diálogo, que surge das questões limítrofes e dos métodos paralelos. Na apresentação de 1990, Barbour refere-se a diálogo quando fala de interações indiretas entre religião e ciência. Um exemplo conhecido desse modo é a teoria científica do Big Bang e a doutrina bíblica do início do mundo no tempo. É a partir do modo do diálogo que Barbour (1990, 2000) explicita a convicção de que certamente a partir do reino da vida se deve reconhecer não apenas a causalidade downtop, a saber, a dos subsistemas particulares no sistema geral, mas também a causalidade top-down, a saber, a do sistema integral nos subsistemas. Propõe, então, o que denomina causalidademulti-nível ou hierarquia deníveis decausalidade. A causalidadetop-down não desrespeita nenhumalei denível inferior de uma organização, mas responde pela complexidade real do sistema que, na causalidade down-top, sofreria um processo de redução metodológica, epistemológica e ontológica.

Integração é o nome que Barbour utiliza quando fala de interações diretasentre ciência ereligião, quando o conteúdo da ciência e o wnteúdo da religião acabam coincidindo, como no "princípio antrópico" da cosmologia, na teologia natural, ou no "ponto ômega", de Teilhard de Chardin, na teologia cristã da natureza. Segundo Barbour, a maior integração acontecequando "tanto a ciência como a religião contribuem para uma visão de mundo coerente, desenvolvida numa metafísica abrangente" (1990, p. 28), que, embora não sendo nem ciência nem teologia, é um ponto de encontro para uma reflexão comum. $\mathrm{O}$ autor aponta a filosofia do processo, inspiradano pensamento científico eteológico deWhitehead, como promissor ponto de encontro. Essa filosofia inclui mudança, acaso, novidadee ordem, distinção econtinuidade. Deus é a fonte da novidade e da ordem. A criação é um processo longo e incompleto.

Deus eliciaa auto-criação das entidades individuais, permitindo com isso liberdadeenovidade assim como ordem eestrutura. Deus não é o desligado Absoluto, Motor Imóvel, mas interage reciprocamente com o mundo, uma influência em todos os acontecimentos embora nunca a causa única de qualquer evento. (1990, p. 29)

Em seu discurso de aceitação do Prêmio Templeton de 1999, em maio de 1999, em Moscou, Barbour (Herrmann, 1999) organiza um pouco diferentementeas quatro maneiras acima descritas epropõe conflito, independência, assombro ediálogo genuino. A categoria "assombro" resulta do senso de terror e maravilhamento percebido nas descobertas da ciência. O diálogo genuino é exemplificado da forma seguinte:

Selevamosa Bíblia a sério, porém não literalmente, podemos aceitar sua mensagem central sem aceitar a cosmologia pré científica na qual ela foi expressa, como o universo em três camadas,com o céu em cima e o inferno em baixo, ou os sete dias da história da criação. Os autores do Gênesis acreditavam quea morte começou como castigo do pecado humano. Hoje sabemos que a morte estava presente muito tempo antes da chegada dos seres humanos, e que ela era uma necessária característica da criação por evolução. Masnósainda podemos crer que a morte ameaça os seres humanos de um modo singular, intensificado pela violação das relações com Deuse com o próximo, o que constitui o pecado humano. (Herrmann, 1999, p. 3)

\section{Confiança Básica na Inteligibilidade do Mundo}

John Haught (1995), teólogo e professor de Ciência e Religião na Universidade de Georgetown, organiza de forma ligeiramente diferente da de Barbour (1990) a tipologia das relações entre religião e ciência. Distingue eleentre conflito, contraste, contato econfirmação. Conflito e contraste correspondem ao que Barbour denominou de conflito e independência. Haught observa, no entanto, que a disposição a impedir o conflito, própria da posição de contraste, pode desviar a pessoa para duas modalidades 
espúrias de fusão, ou confusão, entre religião e ciência: a quefunde uma na outra ea queas faz concordar a qualquer preço. O "criacionismo científico" ea equivalência dos seis dias da criação com seisépocas da evolução cósmica seriam ilustrações dessas modalidades. Como Haught não percebe aguda distinção lógica entre diálogo eintegração, prefere juntar as duas numa categoria denominada "contato" e acrescentar um quarto tipo, "confirmação", "a fim derepresentar o crescentenúmero de estudos teológicos que descobrem as maneiras mais profundas nas quais a religião e a teologia em princípio envolvem ealimentam 0 inteiro empreendimento científico" (1995, p. 204). 0 contato supõe consonância com a visão científica da cultura contemporânea e promove entre cientistas e teólogos "a conversação aberta, o diálogo e o impacto mútuo, preservando as diferenças, mas cultivando o relacionamento" (1995, p.18). Um exemplo eloqüente de contato é a fé religiosa na promessa feita a Abraão e o desabrochar do universo revelado pela biologia e pela física recentes. A maneira maisfundamental de relação entreciência ereligião é, no entanto, segundo Haught, a da confirmação, queeledefine nesta paráfrase:

A reivindicação que faz a religião de que o universo é uma totalidadefinita, coerente, racional eordenada, fundamentada num amor e numa promessa definitivos, forneceuma visão geral das coisas, que alimenta consistentemente a busca científica do conhecimento e liberta a ciência da associação com ideologias aprisionadoras. (1995, p. 22)

A confirmação, nesse sentido, não serefere a particulares hipóteses ou teorias transitórias, mas à raiz permanente da ciência, queéa confiança na inteligibilidade do mundo. Re assegurar a confiança básica é a tarefa da religião. Nesse sentido, a religião estaria garantindo à ciência sua base insubstituível.

\section{Religião e Ciência em busca do Sentido}

Philip Hefner (1997), redator-chefe deZygon, acredita que hoje em dia cientistas e teólogos compartilham de uma interface que pode ser denominada "busca de sentido". Enquanto as religiões tradicionaisfornecem uma moldura abrangente de sentido, as ciências oferecem uma moldura abrangente de causalidade. São molduras distintas, com convergências e discrepâncias, mas procura-se hoje com interesse acadêmico uma forma de articulá-las. Segundo Hefner, é possível distinguir seis trajetórias na história da interface religião/ ciência na busca de sentido.

1) A opção moderna: tradução da sabedoria religiosa em conceitos científicos.
É a opção dos que pensam, como R. W. Burhoe, fundador de Zygon, que a ciência (natural) e seu método desestabilizaram os esquemas religiosos tradicionais conferidores de sentido; como esses esquemas são essenciais para qualquer sociedade sadia, procuram persuadir os cientistas de que ciência e religião provêm dos mesmos processos evolutivosque selecionaram a ciência para revelar o mundo natural ea religião para comunicar à comunidade humana a sabedoria necessária à sobrevivência. No campo da Psicologia, ficou famosa a polêmica posição de Campbell (1975), presidente da American Psychological Association, que sustentava ser a sabedoria das tradições religiosas, que ensinam a disciplina e a contenção, guias de vida mais confiáveis que as psicoterapias atuais.

2) A opção pós-moderna: construção de novos mitos, baseados na ciência.

O utros pensam que as religiões tradicionais não mais são adequadas a dar sentido à vida de hoje. Falam, por exemplo, de 'a-mitia', falta de mito, ausência de esquemas amplos de sentido na sociedade hodierna. É, pois, necessário construir novos mitos, baseados no pensamento evolucionário eadequadosao pluralismo global. Esses mitos seriam inspirados, por exemplo, na cosmologiado BigBang, nas teorias bioquímicas do surgimento da vida, enas ciências ecológicas. O mito não precisaria ser verdadeiro no sentido moderno: bastaria ser acreditado, como um 'nobreengano', e garantir, com isso, a sobrevivência da humanidade.

3) A opção crítica pós-iluminista: expressão da verdade na linha de chegada da ciência.

Há os que pensam, criticando a posição iluminista, que não é mais necessário construir mitos ou outras formas de visão abrangente, como a própria ciência, pois o conhecimento acaba ficando reificado e tirânico. A religião, ao contrário, embora não se oponha à ciência, não tem sua pretensão de conhecimento acabado: nas "margensobscuras" do conhecimento autorizado da ciência, a religião pressente, entreaberta, uma transcendência.

4) A opção construtivista pós-moderna: o modelo de uma nova metafísica para o conhecimento científico.

Outros propõem uma nova metafísica para a ciência, sem almejar construir um novo mito abrangente, como na trajetória 2. Partem eles da convicção de que as ciências, desenvolvidas no O cidente, nasceram intrincadas com visões de mundo ou suposições metafísicas distantes de nossa real experiência científica, pessoal e social. As feministas, por exemplo, sustentam que os conceitos metafísicos de hierarquia e finalidade derivam mais do sistema patriarcal do que da realidade física. Outros pensam que a distinção entre sujeito e objeto distorce a relação entre o homem e o ambiente, ou que a suposição de que o todo éum conjunto de partes perde de vista a função orgânica das totalidades. 
Algumas propostas nessa posição são a metafísica do processo (Whitehead, na filosofia; Hartshorne, na teologia), ametafísica feminista do holismo eda corporeidade; a teoria "gaia", da interconexão dos sistemas planetários da terra; a "ordem implícita" na natureza, de D. Bohm.

5) A opção construtivista tradicional: interpretação da ciência com os conceitos dinâmicos tradicionais.

Essa é a opção de muitos teólogos, inclusive teólogoscientistas como os da Ordem dos Cientistas Ordenados (Ex.: o físico J. Polkinghornee o bioquímico A. Peacocke), que tentam interpretar o conhecimento científico com os conceitos cristãos tradicionais, e esses conceitos à luz do conhecimento científico. A base dessa opção é a de que as visões de mundo tradicionais, em particular a cristã, não estão de modo algum exauridas, podendo sua substância ser reinterpretada para abrigar o conhecimento científico que refez o modo de ver o mundo. Exemplo: a teoria do Big Bang descreve um mundo contingente, cujo caráter fundamental seria examinado pela teologia; a dinâmica do caos e a física quântica apontam para uma lacuna no âmago das coisas, consistente com a afirmativa teológica da ação de Deus na natureza e na história; sob o enfoque da biologia, outros sustentam que a ação criadora de Deus deveria ser entendida como a tendência de fazer surgir, de fases mais simples da evolução, formas cada vez mais complexas.

6) A opção cristã evangélica: reafirmação da racionalidadeda crença tradicional.

Finalmente uma das mais dinâmicas e brilhantes trajetórias, segundo Hefner (1997), é composta de filósofos e teólogos cristãos "evangélicos", assim denominados por pertencerem, em grande parte, ao cristianismo predominantenos Estados Unidos ena Grã-Bretanha. Esses estudiosos procuram demonstrar que o domínio da ciência nos séculos XIX e XX não tornou a fé cristã comum menos aceitável ou compreensível. Hefner salienta duas linhas típicas deargumentação: a) os cientistas muitas vezes partem de suposições problemáticas do ponto de vista lógico, como quando argumentam que a evolução prova que Deus não existe ou que o cosmos é a realidade fundamental; b) tanto a ciência como a religião revelam estruturas de racionalidade viáveis.

\section{O Cientista como Ser Humano}

Em relação à Psicologia a questão religião/ciência assume diversas feições. A Psicologia tem uma dimensão que a aproxima das ciências naturais e biológicas e outra dimensão que a aproxima das ciências históricas e hermenêuticas. Exemplos nítidos seriam a neuropsicologia e a psicologia cognitiva da inteligência artificial, de um lado, e, de outro, a psicanálise e as diversas psicoterapias.
Schafranske (1997) resume muito bem essas duas faces recorrendo a Habermas, que distingue as duas modalidades de ciência pelo método de atingir seu objeto: as ciências empírico-analíticasconstroem etestam suasteorias baseandose na co-variância de eventos observáveis, ao passo que as ciências histórico-hermenêuticas têm "acesso aos fatos por meio do entendimento do sentido, e não pela observação" (Schafranske, 1997, p.162). Em relação à religião eà busca desentido, a psicologia encontra-semaisvizinhana dimensão histórico-hermenêutica, onde, assim como a religião, "produz conhecimento, desperta motivação e muitas vezes leva à transformação pessoal" (1997, p.163). Porém essa dimensão não pode ser vista como separada da outra: "o que parece estarmos aprendendo por meio da pesquisa em neurociência éque as explicações do cérebro podem acabar exigindo termos tais como crenças, desejos e sentimentos, bem como neurônios, sinapses e serotonina" (M. Schechtman, citada em Shafranske, 1997, p.163). Apoiando-se na teoria multi-nível de Barbour (1990), Schafranske oferece a perspectiva integrada de queéa partir do self que os acontecimentos no cérebro evoluem para significadospsicológicos, dentre os quais o da busca de sentido.

Existe ainda uma terceira feição da Psicologia, que éa que estuda a psicologia do cientista, inclusivea psicologia do cientista em seu posicionamento frente à religião (Paiva, 2000). Em pesquisa conduzida por meio de entrevistas em profundidade com docentes-pesquisadores da Universidade de São Paulo, verificamos que as razões de aceitação ou rejeição da religião, sob a forma tradicional ou outra, não foram determinadas por decisões denatureza epistemológica, seja da ciência seja da religião, nem pelas alegadas diferenças de atitude exigidas por uma e por outra. Essas diferenças deatitudefavoreceriam, por exemplo, a independência, a liberdade, o espírito crítico, o questionamento, a tolerância, no caso da ciência; favoreceriam a submissão, o compromisso, a intolerância, no caso da religião (Paiva, 1995, 2000). Ao contrário do que a mídia faria esperar, os cientistas, físicos, zoólogos ou historiadores, não opuseram o conhecimento científico à opção religiosa ou irreligiosa. Partindo do conceito de conflito, queécostumeiro na apresentação do tema ciência/ religião, não encontramos nenhum conflito de ordem cognitiva, seja porque religião não fazia parte do universo mental do cientista, seja porque, embora reconhecida como fazendo parte do universo mental de outros cientistas, não chegava a afetar o entrevistado, seja porque religião eciência eram julgadas regiões não relacionadas uma com a outra, seja porque atribuíam um âmbito à religião (o por que) e outro âmbito à ciência (o como). O s conflitos encontrados, e numerosos, foram detectados de forma indireta, no que podemos localizar como o préconsciente e o inconsciente 
dos pesquisadores. Aí, porém, revelaram-se não como conflitosdientíficos, mas como conflitos humanos. É enquanto sereshumanosqueos cientistas experimentaram dificuldade não com qualquer realidade divina e religiosa, mas especificamente com a idéia cristã de Deus. O s resultados, com efeito, deixaram claro que os cientistas não têm dificuldade em aceitar uma divindade impessoal e cósmica, dotada de sabedoria e poder e ordenadora do mundo. Uma boa parte deles rejeitava, contudo, a idéia de um Deus/ pai que estabelece a lei. Essa terceira feição da Psicologia parecemais própria a ela, enquanto a destaca da ciência em geral, e da relação entre ciência e religião, e a reconhece no exercício de sua função particular: 0 estudo do comportamento humano.

\section{Referências}

Barbour, I. (1966). Issues in scienœ and religion. Englewood-Cliffs: PrenticeHall.

Barbour, I. (1990). Religion in an age of scienœ. The Gifford Lectures 19891991 (Vol. I). San Francisco: Harper.

Barbour, I. (2000). When scienœ mets religion: Enemies, strangers, or partners? New York: HarperSanFrancisco.

Campbell, D. T. (1975). On the conflicts between biological and social evolution and between psychology and moral tradition. American Psychologist, 30, 1103-1126.

Haught, J. F. (1995). Scienœ \& religion: From œnflict to œnversation. New York: The Paulist Press.

Hefner, P. (1997). The science-religion relation: Controversy, convergence, and search for meaning. International Journal for the Psychology of Religion, 7, 143-158

Herrmann, R. L. (1999). 1999 Templeton Prize Awarded in Moscow. Progress in Theology. The Newsetter of the John Templeton Foundation, 7(4), 1 3.
Horgan, J. (1997). The end of scienœ. Facing the limits of knowledge in the twilight of the scientific age. New York: Broadway Books.

Hutchinson, W. R. (1991). Encyclopedia of American Religious Experience. Religious Studies Review, 17, 115-119.

Jones, S. L. (1994). A constructive relationship for religion with the science and profession of psychology: Perhaps the boldest model. American Psychologist, 49, 184-199

Larson, E. J. \& Witham, L. (1997). Scientists are still keeping the faith. Nature, 386, 435-436.

Larson, E. J. \& Witham, L. (1998). Leading scienists still reject God (Correspondence). Nature, 394, 313.

Larson, E. J. \& Witham, L. (1999). Scientists and religion in America. Scientific American, 281(3), 78-83.

Leuba, J. H. (1916). Thebelief in God and immortality: A psychological, anthropological and statistical study. Boston: Sherman, French \& Co.

Marsden, G. M. \& Longfield, B. J. (Orgs.) (1992). The secularization of the academy. New York/Oxford: Oxford University Press.

Paiva, G. J.de (1995). Ciência e religião na academia. Ciência Hoje, 19(112), 1545.

Paiva, G. J.de (2000). A religião dos cientistas. Uma leitura psiológica. São Paulo: Loyola.

Polkinghorne, J. (1998). God in an age of scienœ. New Haven/London: Yale University Press.

Shafranske, E. P. (1997). Practices in the search for meaning: A response to Hefner. International Journal for the Psychology of Religion, 7, 161-166.

Templeton, J. M. \& Giniger, K. S. (Orgs.) (1998). Spiritual evolution: Scientists discuss their beliefs. Philadephia/London: A Giniger Book/Templeton Foundation Press.

Sobre o autor

Geraldo José de Paiva éLivre-D ocente e Professor Associado do Instituto de Psicologia da USP, com Pós-doutorado em Psicologia da Religião na Université Catholique de Louvain-la-Neuve, Coordenador do GT Psicologia \& Religião, da ANPEPP, e Presidente do Grupo de Pesquisa do CNPq "Laboratório de Psicologia Social da Religião".

Recobido: $11 / 01 / 2002$

Revisado: $16 / 04 / 2002$

Aceite Final: 14/05/2002 